\title{
Opening up Corporate Foresight: What Can We Learn from Open and User Innovation?
}

\author{
Sabrina Korreck \\ Sabrina.Korreck@uni-hamburg.de|Faculty of Business, Economics and Social Sciences, University of \\ Hamburg, Von-Melle-Park-9, 20146 Hamburg, Germany
}

\begin{abstract}
Organizations find themselves in a fast-paced and increasingly complex and uncertain environment. Hence, they engage in foresight to understand weak signals and developments that may affect them in the medium to long run and build up "strategic preparedness". Literature on open and user innovation has described methods to tap into external knowledge sources and some have potential to enhance foresight results, but research has not yet fully benefitted from these insights. Thus, the aim of this article is to synthesize findings from both literatures and explain why users and user collectives are a valuable knowledge source for foresight. The contributions of the paper are twofold. First, the paper provides a typology of methods, which are suitable for drawing on user knowledge. Second, the identified methods are compared with one another in terms of advantages, disadvantages and boundary conditions.
\end{abstract}

Keywords. Open Foresight; Distributed Information Sources; Corporate Foresight; Innovation Management; User Innovation.

Cite paper as: Korreck, S., (2018). Opening up Corporate Foresight: What Can We Learn from Open and User Innovation?, Journal of Innovation Management, www.open-jim.org, 6(3), 153-177. http://hdl.handle.net/10216/116396 


\section{Introduction}

In a rapidly changing world, corporate foresight represents a promising approach for organizations to identify emerging changes in their environment early and act accordingly in a timely manner. As firms develop an understanding of weak signals, trends and developments that may affect their business in the medium-to-long run, they build up "strategic preparedness" and prevent discontinuities that may come to them as a dangerous surprise (Ansoff, 1975). In addition, foresight helps organizations to recognize and exploit emerging opportunities more quickly and, thus, foster the firm's innovation capacity. Ultimately, organizations that keep a good vision on what is happening at their periphery can gain tremendous advantage over rivals (Day \& Schoemaker, 2005).

Corporate foresight has continuously evolved over time (Rohrbeck et al., 2015). Foresight was typically conducted by firm managers and internal employees, and sometimes external sources such as networks (Reger, 2001) as well as analysts and consultants (Rohrbeck et al., 2015). Other external sources such as (lead) users, user collectives (e.g. communities and crowds), suppliers, buyers, research institutions, partner firms or even competitors have so far rarely played a role. This is remarkable, given that advances in information and communication technologies, among other factors, have increased the potential and decreased the costs of conducting searches for external sources (West \& Bogers, 2013). Research on open innovation (e.g. von Hippel, 1988, 2005; Chesbrough, 2003; Baldwin \& von Hippel, 2011) described how different approaches to source knowledge from external sources can help firms to support their innovative activities. Some of them have significant application potential to enrich 'established' foresight, but research has not yet fully benefitted from these findings.

Thus, this paper picks up on this need for investigation of those methods, which can be used for foresight. However, since open and user innovation literature is an umbrella term, which encompasses many different methods and knowledge sources, trying to evaluate all of them would be clearly beyond the scope of one single article. Thus, the paper narrows its focus to methods that rely on knowledge of users and user collectives. Using a conceptual approach, the paper builds on a synthesis of previous findings from foresight as well as open and user innovation literature. In the context of the first research question, the paper seeks to identify: Which methods are suitable for sourcing user knowledge for foresight? However, no universal methodology or 'offthe-shelf' approach exists and the selection of suitable methods always depends on the firm's specific objectives (Slaughter, 2002; Magruk, 2011). Therefore, the paper seeks to answer the second research question: What are the advantages, disadvantages and boundary conditions of these methods?

The paper is structured as follows: In the next section, a literature review on foresight, which is currently developing towards a more open understanding, is presented. The third section highlights why users are highly qualified sources of knowledge and why opening up foresight to users holds potential to improve foresight practice. In the fourth section, a typology of open foresight methods that are suitable for drawing on knowledge of users and user collectives is provided. In the fifth section, these methods are compared with a view to their advantages, disadvantages and boundary conditions. This discussion is structured along the following key design dimensions: 
(1) number of users involved, (2) mode of interaction, (3) governance mechanisms, and (4) type of incentives. Finally, the sixth section concludes and suggests areas for further research.

\section{Moving from Foresight to Open Foresight}

In order to ensure their survival in today's highly dynamic world, companies need to be able to detect changes and react to these early (Nelson and Winter, 1982). Against this background, foresight implies a readiness to deal with long-term issues (Miles, 2010) by providing firms with a basis enabling them to adapt to unfolding environmental changes. Often vague information exists, which foreshadows the occurrence of later events and developments. Information progressively develops and improves over time, but the later a firm reacts, the more likely it will be too late in making important decisions. Ansoff (1975) points out that the time remaining before the impact on the firm passes a critical benchmark is crucial: "For a threat this benchmark may be the level of loss beyond which the firm's survival is threatened; for an opportunity the point beyond which the cost of "climbing the bandwagon" can no longer be recovered through profits" (p. 24). Thus, through an improved awareness of so-called weak signals, foresight allows firms to act in a timely manner and have their responses better planned and executed in order to seize opportunities and avert dangers.

Foresight is an approach to anticipate possible future developments. However, there is no unified or commonly accepted definition of foresight. Instead, a broad variety of different definitions or similar expressions exist, which often denote different activities in firms (Reger, 2001; Amsteus, 2008). Ehls et al. (2016) give an overview of definitions and point out that the concept has so far been referred to as a tool, a process, or an ability. Horton (1999) outlines that foresight involves gathering relevant information about possible future events and developments that may possibly affect the organization in the medium-to-long term. Thus, foresight typically takes a holistic view, i.e. it looks beyond the close and immediate market environment in order to consider political, economic, social, and technological ("PEST") factors. The resulting knowledge is then translated and interpreted in order to understand possible environmental changes and their implications. Finally, foresight involves a commitment to action, i.e. newly discovered insights lead to concrete action, which brings benefits to the organization (Horton, 1999). In that sense, foresight is perceived as an action-oriented approach that does not aim at predicting or forecasting the future, but supports individuals in thinking about different possible future states (Vecchiato, 2012).

Foresight activities can benefit companies in multiple ways. Voros (2003) points out that by opening up an expanded range of perceptions of available options, foresight can make strategymaking potentially wiser (Voros, 2003). Rohrbeck and Gemünden (2011) identified three roles through which foresight activities can enhance a firm's innovation capacity. First, foresight can play the initiator role, i.e. "foresight triggers innovation initiatives by identifying new customer needs, technologies, and product concepts of competitors" (p. 237). Second, foresight can play the strategist role, i.e. "foresight directs innovation activities by creating a vision, providing strategic guidance, consolidating opinions, assessing and repositioning innovation portfolios, and identifying the new business models of competitors" (p. 237). Third, foresight can play the opponent role, i.e. "foresight challenges the innovators to create better and more successful 
innovations by challenging basic assumptions, challenging the state-of-the-art of current R\&D projects, and scanning for disruptions that could endanger current and future innovations" (p. 237). Rohrbeck and Kum (2018) conducted a longitudinal analysis and found strong empirical evidence that foresight leads to higher future preparedness and ultimately enables superior firm performance.

Experts agree that no universal methodology for conducting foresight exists (Magruk, 2011). There is no satisfactory 'off the shelf' solution and foresight will take different shapes and forms in different organizations to reflect firms' goals and specific needs (Slaughter, 2002). Numerous methods are available for exploring possible alternative futures and literature on traditional foresight often focused on scenario technique, roadmapping, and the Delphi method, amongst others. Methods differ in their fundamental attributes. On the one hand, Popper (2008) distinguishes between qualitative, quantitative and semi-quantitative methods and finds that the use of qualitative methods is most popular, "due to the fact that the study of the future is inevitably informed by opinions and judgements based on subjective and creative interpretations of the changes (or lack of changes) creating or shaping the future" (p. 70). On the other hand, building on Georghiou's (2001) typology, Popper (2008) distinguishes foresight methods regarding their capability to gather or process information based on evidence, creativity, expertise, or interaction. Foresight methods consist of these capabilities to different proportions. In many cases, foresight methods complement each other and, thus, a combination of methods is often selected. Hines and Bishop (2013) developed a framework as a meta-method, which helps carrying out foresight in a logical flow and allows substitution of methods in a modular fashion. Another foresight process framework, which outlines distinct phases, has been put forward by Voros (2003).

Research on foresight has over time continuously advanced in both theory and methodology (Reger, 2001; Rohrbeck et al., 2015). Previously, foresight was typically conducted within the firm's organizational boundaries and involved mostly internal managers and employees and only some additional experts and consultants. However, internal actors often have difficulty to perceive possibly impactful information, as they are focused on day-to-day business or are locked in prevailing mindsets and power structures of the organization; in addition, the value of expert judgment in foreseeing change is disputed (Rau et al., 2014).

In the meantime, advances in and a growing availability of information and communications technologies have facilitated approaches to integrate externals into innovative activities (Dodgson et al., 2006). Likewise, information and communication technologies are likely to revolutionize the foresight practice (von der Gracht et al., 2015). It appears that foresight practice increasingly evolves into a more open direction, thereby increasingly utilizing new methods to source futurerelated knowledge from external knowledge sources. In consequence of this development, foresight research takes up many insights, which have previously been elaborated in the literature on open innovation (for a review see e.g. Dahlander \& Gann, 2010; Huizingh, 2011; West \& Bogers, 2013). At the heart of this stream of research lies the idea that companies should become more open to external knowledge and ideas (Chesbrough, 2003). The meaning of openness relates to a broader debate on the boundaries of the firm and is expressed through various forms of relationships with external actors (Dahlander \& Gann, 2010). For instance, the literature has documented involvement of (lead) users (Gassmann et al., 2006; Grimpke \& Sofka, 2009), communities, crowds, 
suppliers (Li \& Vanhaverbeke, 2009; Schiele, 2010), buyers, research institutions (Fabrizio, 2009; Cassiman et al., 2010; Harryson et al., 2008), partner firms or even competitors (Lim et al., 2010). Advances in information and communication technologies (particularly the Internet and social media) facilitated access to distributed knowledge and enabled novel approaches to source knowledge from, or collaborate with, external sources. Among the most important open innovation approaches are, for instance, crowdsourcing (Afuah \& Tucci, 2013; Bayus, 2013; Boudreau \& Lakhani, 2013; Piezunka \& Dahlander, 2015), co-creation (Sawhney \& Prandelli, 2000; Prahalad \& Ramaswamy, 2004; Füller et al., 2009), and online communities (Janzik \& Raasch, 2011; Kim, 2000).

Some of the methods described in the open and user innovation literature can also be used to explore alternative futures and hold potential for enhancing current foresight practice. Thus, the concept of "Open Foresight" as first coined by Daheim and Uerz (2008) refers to "the next phase of corporate foresight", which is "based on the assumption that businesses can shape future contexts and markets by anticipating through an open dialogue the dynamic interaction between social, technological and economic forces" (Daheim \& Uerz 2008, p. 332). Mietzner (2009) differentiates between closed and open foresight, with open foresight referring to the opening of the process to utilize the firm's outside world. Miemis et al. (2012) refers to open foresight as a "process for analyzing complex issues in an open and collaborative way" (p. 92). Ehls et al. (2016) identify three defining elements, which include (1) the systematic use of distributed information sources in order to anticipate the future corporate business environment, (2) which is institutionalized within the organization and often conducted with outside actors, and (3) draws especially on insights and methods from the open and user innovation research. Wiener et al. (2018) and Wiener (2018) focus on the necessary organizational context and culture, which is are an important precondition for a company's openness towards external sources. In addition, the concept has appeared in few practice-oriented articles (Rau et al., 2014; Gattringer \& Strehl, 2014a, 2014b; Rudzinski \& Uerz, 2014). A related term that also emerged together with the rise of the 'open' paragdigm is "networked foresight", which refers to foresight conducted in innovation networks (van der Duin et al., 2014; Heger \& Boman, 2015). Overall, little research on open foresight has been conducted so far. In particular, research has not caught up on new possibilities that enable the sourcing of user knowledge.

\section{Benefits from Integrating Users and User Collectives as Know- ledge Sources}

In order to explore alternative futures, firms can get valuable input from individual (lead) users or tap the rich source of knowledge available in various different user collectives, such as (online) communities or crowds. The definition of users underlying this article covers not only the firm's own users, but also users from analogous markets, who face trends similar to that of the target market (Franke et al., 2013), as well as some nonusers, who are very knowledgeable about relevant future-related topics. Prior to the discussion of possible open foresight methods, an understanding of users' competences and knowledge is needed and of how their integration can potentially enhance foresight results. 
Boundedly rational actors tend to conduct local searches, i.e. they look for solutions in the surroundings of their current position (Cyert \& March, 1963; Nelson \& Winter, 1982; Stuart \& Podolny, 1996; Katila, 2002; Katila \& Ahuja, 2002). However, when firms draw only on previous experiences, established views, already existing knowledge and familiar routines, they will only take into consideration a narrow solution space. Regarding foresight, this implies a high probability of blind spots remaining, and of potential harmful developments being ignored or promising opportunities being missed.

Diversity is a critical component of innovative capabilities (Cohen \& Levinthal, 1990) in general. This also applies to foresight, where the "attempt to accommodate diverse perspectives on the future is central to the methods for the scanning of weak signals" (Könnölä et al., 2007, p. 611). Through the involvement of actors with diverse perspectives, the potential solution space can be significantly broadened. In this way, "Opening up the foresight activities to externals is a promising way to detect blind spots" (Rau et al., 2014, p. 31). A study by Jeppesen and Lakhani (2008) confirms the importance of involving people with alternative knowledge. In the context of a "broadcast search" problem, when information is disclosed widely and everyone is invited to participate, they examined which external solvers are able to provide successful solutions. They found that individuals, who come from a field of expertise that is far from the focal field of the problem, are more likely to come up with successful solutions than actors in the source problem field. As they are not bound to current thinking in the field of the focal problem, marginal persons can offer perspectives and heuristics that are novel and therefore useful for generating solutions to these problems.

Besides adding a novel perspective to foresight, users possess specific knowledge, which is very valuable to firms. Users can be considered as experts regarding need-related information, as they know their needs best and have the fullest information about how they want to use a certain product. In contrast, manufacturers possess information about solution possibilities as well as the production process itself. This means that users and manufacturers tend to draw on different local information when they innovate. However, bridging need and solution information between users and manufacturers is often very difficult, because information is sticky, i.e. it is costly to transfer a given piece of information to a specific location in a form useable by a knowledge seeker (von Hippel, 1998). In order to minimize costs incurred in connection with understanding user needs, it is therefore advantageous to source information from its origin and integrate user knowledge as closely as possible into the foresight process.

However, not all users are equally helpful. A crucial distinction between typical and lead users dates back from seminal work by von Hippel (1986). He had observed that typical users of a firm's existing products are not well positioned to assess new product needs and potential solutions. Typical users have a limited ability to conceive novel attributes and uses because they are too familiar with existing product attributes and constrained by their present real-world experience. In contrast, lead users "are familiar with conditions which lie in the future for most - and so are in the position to provide accurate data on needs related to such future conditions" (von Hippel, 1986, p. 796). Lead users have needs that foreshadow the general demand in the marketplace, but face such needs months or years before the bulk of that marketplace encounters them. This ability makes lead users an important knowledge source for foresight. By utilizing knowledge 
from lead users, a firm is better equipped to perceive changing habits and preferences of users and socio-cultural trends.

Lead users have a second important characteristic: As they are dissatisfied with the current market offering, they benefit significantly by obtaining a solution that caters to their needs (von Hippel, 1986). As they expect an innovation-related benefit, lead users are motivated to provide - and often freely reveal at no cost - information and contribute to the development of new products and services (von Hippel, 1986; von Hippel, 1988; Urban \& von Hippel, 1988; Morrison et al., 2000; Morrison et al, 2004; Franke \& Shah, 2003). Some lead users even develop their own innovations and their ideas were found to be more commercially successful as compared to ideas generated by traditional marketing research methods (Lilien et al., 2002). Even though foresight does not immediately aim at generating new ideas and new innovative products, it can be assumed that the incentive associated with obtaining a solution to lead users' needs still plays a role and motivates them to contribute to foresight.

Further research investigated the nature of lead users as well as the consequences of lead userness. Schreier and Prügl (2008) found that lead users are often characterized as having innovative personalities, breaking with accepted modes of thought and action and discovering both problems and avenues of solution. In addition, they found that lead users tend to adopt new products faster and more heavily than ordinary users. Being an early adopter implies that lead users can act as opinion leaders, i.e. they can, combined with their importance as communication sources, play an important role in the diffusion process of newly launched products (Morrison et al., 2004). In that sense, lead users may influence (and perhaps even set) trends, which makes them an even more valuable source for foresight.

\section{Methods for Drawing on User Knowledge}

A growing body of literature on open innovation documents how companies reach beyond their organizational boundaries to search for knowledge from external actors. Many of these methods are also suitable for foresight and allow firms to utilize user knowledge for exploring possible alternative futures. In the following, the paper describes how firms can conduct foresight with lead users as well as community-based and crowdsourcing approaches. The methods partly complement each other and can be combined in many ways. In addition, some well-established methods from more "traditional" foresight exist, which can now be conducted in a significantly more open way or incorporate elements from open innovation.

\subsection{Open Foresight with Lead Users}

The characteristics of lead users laid the basis for the development of the lead user method (von Hippel, 1986). The method aims to incorporate lead users in the fuzzy front end of the innovation process in order to learn more about emerging needs and, thus, help firms generate ideas and concepts for new products and services. The methodology involves four steps and starts with a definition of the search field and of the goals and requirements directed towards the outcome of the process (Lüthje \& Herstatt, 2004). In the next two steps, relevant trends as well as lead users, who lead these trends, have to be identified. In order to identify lead users, firms 
can use the pyramiding approach, which is a variant of snowball sampling that involves asking individuals with a given attribute (in this case: lead user characteristics) to identify one or more others who they think has higher levels of the sought-after attribute (von Hippel et al., 2009). At the end of the process, identified lead users are invited to workshops, where they discuss and collaboratively develop new product concepts together with company employees.

Trend analysis and identification are important functions of foresight; thus, it can be stated that foresight is already part of the lead user method. Previous research has clearly pointed out that, since lead users are familiar with future conditions, they are well-equipped to "serve as a need-forecasting laboratory" (von Hippel, 1986, p. 791) and "can be harnessed for forecasting purposes (Morrison et al., 2004, p. 361). Thus, while the lead user method relies on interviews with experts as well as secondary information sources such as academic publications, data banks and the internet for trend forecasting (Lühtje \& Herstatt, 2004), one can argue that, in general, lead users themselves can contribute valuable input to the discovery of trends and open foresight. In order to conduct foresight with lead users, the lead user method needs to be adjusted as follows: At first, the search space has to be defined. In a second step, lead users, who are particularly knowledgeable in the specified search field, have to be identified. Finally, lead users are to be involved in the exploration of possible futures and trends. Rau et al. (2014) focus on foresight workshops as appropriate means of opening up foresight processes and enabling collaborative action. In the workshops, more "traditional" foresight methods can be employed. For instance, lead users can provide valuable input for creativity methods (such as brainstorming) or support the elaboration of scenarios.

Apart from the possibility to conduct physical foresight workshops, identified lead users can be interrogated as experts on future needs. To this end, interviews or surveys can be conducted. Of particular importance for foresight is the Delphi method, which relies on an anonymous group of experts, who will be asked to assess possible future states (Cuhls, 2012). Such a group may consist of lead users serving as experts. The Delphi method consists of at least two rounds; in the second round, participants will receive feedback on the other experts' opinions from the first round. In order to achieve consensus, the experts have the possibility to revise their initial assessment. The Delphi method can be modified by including additional open innovation elements ("Open Delphi"), such as an Internet-based research community (Stockinger, 2015).

Another method to obtain trend-related information from lead users is through informal networking with lead users. Once identified, lead users can be directly approached at conferences or events or be contacted online via email or social networking sites such as LinkedIn, Facebook or Google+. In addition, some lead users may be active in Twitter or maintain blogs, whereas firms can follow their tweets and postings. For instance, Hanke and Möhrle (2013) have analyzed blogs as a source of information for trend identification.

\subsection{Open Foresight Methods Involving User Communities and Social Networks}

Communities are voluntary associations where members interact with each other to acquire and exchange information about a topic of common interest. While various types of communities exist, open innovation literature has focused on those involved in creating innovation outside the boundaries of the firm (West \& Lakhani, 2008). Much information discussed and exchanged 
in communities is usable, accessible and even valuable for companies (Füller et al., 2006). For instance, as users articulate their general satisfaction and complaints, report bugs and problems or share ideas for improvement and novel products and features, communities can be a rich source of information for innovation and new product development. Likewise, in some communities users discuss future-related issues, which provides relevant and valuable input for open foresight. Some communities, such as professional futurist associations or informal groups (e.g. organized via meetup.com) gather offline. However, as the Internet enables communication and collaboration between members from all over the world, most communities have an online presence.

One possibility for firms, which intend to utilize online communities as a source of information for foresight, is to rely on existing third-party communities and observe the dialogue and interactions of members taking place. This approach is referred to as netnography and was pioneered by Kozinets (1998). Initial steps of the method (Kozinets, 2002) involve formulating research questions, identifying relevant communities that are appropriate for answering this question and familiarizing with the community. Subsequent data collection includes retrieving copies of the publicly available online dialogue as well as taking field notes on observations. The data needs to be filtered in order to include only informational and on-topic information (here, future-related information is particularly relevant), and the data collection continues until a point of saturation is reached. Finally, the content retrieved from the community dialogue is analyzed and interpreted to understand the needs of community members and identify relevant trends. Zeng (2018) applies a netnographic approach to the case of an online community in the field of renewable energy. He finds that fruitful discussions take place in the community and that it is possible to derive trends and use the members' input for foresight issues.

Unobtrusively observing communities relates to the broader phenomenon of social media monitoring. In different social networks such as Facebook, Google+, LinkedIn or Twitter, online user interactions are recorded and stored in archives, which represent an under-exploited resource for foresight (Cachia et al., 2007). This massive amount of data from social networks, often combined with data from additional sources, is usually termed "big data" and can be analyzed to detect trends and developments with high predictive value. As Drexler et al. (2014) point out, "Big Data isn't just a description of huge amounts of data; it is about identifying and understanding the relations and correlations among pieces of information, and it's about predictions" (p. 304). Through aggregation and extrapolation of data, patterns can be recognized and, thus, changing habits und trends in social behavior be identified. For instance, Asur and Huberman (2010) demonstrated Twitter's predictive power. While the available amount of data is increasing at fast speed, many sophisticated tools for data mining, social media monitoring and analytics are now available to help make sense of the data.

Apart from the possibility of monitoring communities and social networks, firms can become more directly involved by taking on a privileged position through sponsorship of existing communities, or through creation of their own communities (West \& Lakhani, 2008). Against this background, corporate employees join interactions with community members to brainstorm and stimulate dialog on future-related issues or elaborate shared visions about how users imagine the future will look like. Hence, communities and social networks "could operate as a large-scale method for online brainstorming, a text-bed for future concepts, ideas, assumptions or scenarios" (Cachia et al. 2007, p. 1196). 


\subsection{Crowdsourcing Methods for Open Foresight}

Another way of sourcing user knowledge for open foresight is through 'crowdsourcing'. The underlying idea is that a task, which was traditionally performed by a designated agent (usually an employee), is outsourced to an undefined, generally large group of people by way of an open call (Howe, 2006). After the problem has been broadcast, typically via a web-based platform, members of the crowd self-select to solve the problem and submit their ideas, suggestions for improvement or concrete solutions. Different approaches of crowdsourcing exist, which are also applicable to open foresight.

One type of crowdsourcing is collaboration-based, where many heterogeneous individuals work together towards a shared solution. This is common in many projects in open source software development (Lakhani \& von Hippel, 2003; von Krogh et al., 2003; Belonzon \& Schankermann, 2012). Another well-known example is Wikipedia, where thousands of volunteers collaborate, interact and assist each other to build the world's largest online encyclopedia (e.g. Tapscott \& Williams, 2006). Similarly, wikis and databases that are elaborated in collaboration can be used to collect knowledge for foresight. Schatzmann et al. (2013) mentions "wildcard databases, prediction databases, trend databases, databases that are used for horizon scanning and databases that are used for mapping strategic Foresight" (p. 6). One concrete example the so-called "TrendWiki", which was set up as a crowdsourcing tool for reporting weak signals of change (e.g. an interesting blog post about new innovation, an interesting aspect heard at a conference, or even just the fact that someone noticed a change in how traffic patterns are shifting) (Hiltunen, 2011). The results are shared, commented upon, refined or expanded and then the organization's foresight team meets twice a year to cluster signals into patterns and phenomena. Although the TrendWiki is designed for employees from all over the world to report weak signals, the approach can also be conducted with users.

Another type of crowdsourcing is tournament-based, where many heterogeneous individuals work on a task or problem and compete for the best solution, which then wins a price. For instance, companies set up their own platforms to let a large crowd of users brainstorm for ideas, as highlighted by the case of Dell Idea Storm (Bayus, 2013). In other cases, when facing specific technical challenges, companies use the service of intermediaries for broadcast search among experts (e.g. Innocentive case in Jeppesen \& Lakhani, 2008). Similarly, principles of tournamentcrowdsourcing can be applied to collect information about weak signals and future information. This can be achieved for instance, through idea-spotting networks such as springwise.com and trend-hunter.com, where idea spotters can register and report their observations about ideas, innovations and startups (Hiltunen, 2011). The best ideas will be published and spotters will receive rewards for good spottings.

Prediction markets offer another crowdsourcing approach, which can be applied to diverse areas, such as forecasting future political (e.g. election results), economic (e.g. interest rates; sales), social (e.g. population development), and technological (e.g. market success of technologies) developments. Prediction markets are web-based applications that work like traditional stock markets: Users buy shares if they expect a future event will occur, or sell shares if they expect a future event will not occur. In real time, demand and supply determine a price, which reflects the likelihood that a certain event or development will occur. The price increases as more participants believe an event or development is likely to occur and, thus, bet (real or virtual) money on it. 
Thereby, prediction markets collect and aggregate judgments of all participants, who feed on all available sources of information such as historical data, forecasts from other approaches, news, individual expectations (Graefe et al., 2010).

Finally, an emerging approach are collaborative forecasting games, which invite a crowd, often several thousands of players, to imagine how certain futures would look like (Schatzmann et al. 2013; Rau et al., 2014). The Institute for the Future (IFTF) has developed the "Foresight Engine" platform to set up games, which simulate different future realities: e.g. a future threatened by "superthreats" (such as in the game "Superstruct"), a future of energy (game "SmartGrid 2025") or a future of health care provision systems (game "Future of hospitals"). Players immerse themselves in these scenarios through e.g. YouTube videos and information made available through Facebook, blogs and wikis. In the tradition of brainstorming, players are encouraged to submit their ideas about the future, and, when others build on these ideas to form chains of discussion, they earn points, awards, and achievements for winning ideas . By aggregating numerous micro-forecasts, a big picture emerges of how the future will possibly look like.

\section{Comparing Open Foresight Methods}

The previous section has provided an overview of possible approaches for implementing open foresight with users and user collectives. On this basis, the present section describes corresponding advantages, disadvantages as well as boundary conditions. The discussion is structured along four key design dimensions according to which methods differ. First, available methods differ regarding the number of involved users, i.e. they use knowledge from individuals or from a collective. Second, methods vary regarding the mode of interaction, as they rely either on active cooperation, unilateral sourcing of knowledge or passive observation. Third, methods (except passive methods) differ with regard to the degree of control they leave a company to influence activities and can also be subdivided into self-organized or more directed forms of governance. Fourth, methods (except passive methods) rely on different incentives to motivate users to contribute to foresight, with both intrinsic and extrinsic motivations existing. Table 1 offers an overview of the four design dimensions and the corresponding methods.

\subsection{Individuals' Knowledge vs. the "Wisdom of the Crowd"}

First, available foresight methods can be distinguished from one another as to the number of involved users, i.e. methods rely either on the sourcing of knowledge from individuals or the knowledge from a collective, i.e. a group or crowd of users.

When a firm decides to tap the rich source of user knowledge, one possible approach is to involve individual users. While typical users are constrained by their present real-world experience, lead users encounter needs significantly earlier than the mainstream. Thus, lead users are particularly qualified to act as experts in open foresight. Just as the lead user method relies on the integration of selected individuals, a limited number of previously identified lead users can be invited for participation in open foresight workshops (Rau et al., 2014). In this context, traditional foresight methods can be applied, i.e. the firm is not required to make significant adjustments to its current foresight practice. However, preparing a workshop and bringing together all participants in one 
place is time-consuming and requires a significant investment of human and financial resources (Lüthje \& Herstatt, 2004). As alternative to having lead users participate in workshops, firms can source their future-related information through interviewing, networking or using social networks to connect and follow. But still, the number of users with whom the firm establishes contact should not get too big, as "maintaining too many relationships is costly and may lead to a diversion of managerial attention" (Dahlander \& Gann, 2010, p. 706). At some point, when the number of experts gets too large, the benefits of integrating external sources may be offset (Wallin \& von Krogh, 2010). In addition, the identification of lead users (von Hippel et al., 2009), who are both knowledgeable and motivated to join foresight activities, is not trivial and remains a challenge. There is also a risk of a selection bias existing, if a firm tends to select lead users, who share their views and, thus, hinders the detection of blind spots.

In contrast, firms can tap the vast pool of knowledge available within a user collective, such as a community or crowd. The Internet and modern information and communication technologies enabled the participation of a large number of people independent of their physical location. As a result, the potential of searching for input from external sources increased and the costs decreased (West \& Bogers, 2014). Through community and social network-based and crowdsourcing approaches or by conducting Delphi with lead users as experts, these technological advances are utilized to source knowledge from a huge number of people. They thus harness the "wisdom of the crowd", which implies that the group or crowd makes more accurate decisions - or, in this context, better predictions - than an isolated individual, no matter how smart or well-informed he or she is. Surowiecki (2004) examined the requirements that are necessary to facilitate the wisdom of the crowd and found that diversity is central, as each person has different pieces of information. Given that all individuals in the diverse and large enough crowd are decentral and decide independently, individual pieces of information can be aggregated such that the resulting crowd opinion is more than the sum of its parts. Since these methods do not require the identification of knowledgeable users, but let the participants self-select, selection bias is avoided. Moreover, utilizing information and communication technologies, these methods tend to be of high value but low cost. Despite these advantages, sourcing knowledge from a group or crowd of users is not the means appropriate for problem solving in any circumstance (Afuah \& Tucci, 2013). For instance, crowdsourcing is appropriate if problems are new, complex, and ill-defined (because underlying information or interrelations are difficult to access) and require a substantial amount of creativity or transfer of analogous knowledge. In contrast, crowdsourcing is a less appropriate mechanism when a "problem is too tacit to be delineated and broadcast or requires a considerable amount of interaction between the seeker and the solver" (Afuah, 2014, p. 75$)$. 
Table 1. Overview of methods

\begin{tabular}{|c|c|c|c|c|}
\hline $\begin{array}{l}\text { Design } \\
\text { Dimen- }\end{array}$ & \multicolumn{4}{|c|}{ Methods } \\
\hline $\begin{array}{l}\text { Number } \\
\text { of } \\
\text { involved } \\
\text { users }\end{array}$ & \multicolumn{2}{|c|}{$\begin{array}{l}\text { Methods for sourcing } \\
\text { knowledge from individuals } \\
\text { - Workshops with lead users } \\
\text { - Interviewing lead users } \\
\text { - Networking with lead users }\end{array}$} & \multicolumn{2}{|c|}{$\begin{array}{c}\text { Methods for sourcing } \\
\text { knowledge from a user } \\
\text { collective } \\
\text { - Open Delphi } \\
\text { Crowdsourcing methods } \\
\text { - Community- and social } \\
\text { network-based methods }\end{array}$} \\
\hline $\begin{array}{c}\text { Mode of } \\
\text { interac- } \\
\text { tion }\end{array}$ & $\begin{array}{c}\text { Interactive } \\
\text { methods } \\
\text { - Face-to-face } \\
\text { workshops } \\
\text { - Active } \\
\text { collaboration in } \\
\text { online } \\
\text { communities }\end{array}$ & \multicolumn{2}{|c|}{$\begin{array}{l}\text { Unilateral sourcing } \\
\quad \text { methods } \\
\text { - Tournament-based } \\
\text { crowdsourcing } \\
\text { - Prediction markets } \\
\text { - Interviewing users }\end{array}$} & $\begin{array}{l}\text { Passive observation } \\
\text { methods } \\
\text { - Netnography in } \\
\text { online communities } \\
\text { - Big data analysis }\end{array}$ \\
\hline $\begin{array}{c}\text { Degree of } \\
\text { control }\end{array}$ & \multicolumn{2}{|c|}{$\begin{array}{c}\text { Methods relying on } \\
\text { self-organization of users } \\
\text { - Collaboration-based } \\
\text { crowdsourcing } \\
\text { - Community and social } \\
\text { network-based methods }\end{array}$} & \multicolumn{2}{|c|}{$\begin{array}{l}\text { Methods leaving control to } \\
\text { direct activities } \\
\text { - Community-based } \\
\text { approaches (when platform } \\
\text { owned by organization) } \\
\text { - Workshops with lead users }\end{array}$} \\
\hline $\begin{array}{l}\text { Incentives } \\
\text { for con- } \\
\text { tribution }\end{array}$ & $\begin{array}{r}\text { Methods relying } \\
\text { intrinsic mot } \\
\text { - Collaboratio } \\
\text { crowdsour } \\
\text { - Community a } \\
\text { network-based } \\
\text { - Forecasting }\end{array}$ & $\begin{array}{l}n \text { purely } \\
\text { ations } \\
\text { based } \\
\text { ng } \\
\text { d social } \\
\text { ethods } \\
\text { ames }\end{array}$ & $\begin{array}{r}\text { Methods } \\
\text { intrins } \\
r \\
- \text { Tou } \\
\text { crowdso } \\
\text { - Worksh }\end{array}$ & $\begin{array}{l}\text { relying on mix of } \\
\text { c and extrinisic } \\
\text { otivations } \\
\text { nament-based } \\
\text { arcing- Prediction } \\
\text { markets } \\
\text { ps with lead users }\end{array}$ \\
\hline
\end{tabular}

\subsection{Active Participation vs. Passive Observation}

Second, open foresight methods vary significantly as to how the organization interacts with the environment. Methods rely on active cooperation, unilateral sourcing of knowledge, or passive observation.

Interactive methods directly integrate the holder of information, i.e. the user, into the foresight process to collaboratively explore possible alternative futures. In this context, interaction between the organization and users is characterized by direct communication and reciprocal exchange. Often, such interaction takes place in face-to-face workshops where participants are given the opportunity to express their thoughts and discuss them with each other. Workshop participants give and receive immediate feedback and build on each other's insights and arguments, so that interaction leads to a self-reinforcing effect of cooperation among actors with 
different knowledge, skills, and experiences (Franke \& Shah, 2003). Moreover, workshops allow for efficient communication between the organization and users, because the immediate interaction provides room to clarify comments and avoid, or at least reduce, misunderstandings and misinterpretations (Rau et al., 2014). Collective creativity flourishes when individuals actively interchange thoughts and expressions, but, originally, such creative environment was only found in a close physical environment (Cachia et al., 2007). Today, favorable conditions for interaction can also be found in online communities where members communicate and exchange their arguments in real-time. A possible disadvantage of interactive methods is, however, that "the personal integration might support psychological group effects such as groupthink, leading to a conformity of opinions" (Rau et al., 2014, p. 30).

A second type of methods relies on the unilateral sourcing of user knowledge. The organization thereby integrates solely the information artifact, but not the person holding the information (Diener, 2014). As neither mutual exchange nor deeper interaction are intended, the role of the user is limited to giving input. Typically, organizations first specify what kind of future-related information they need. Then, the organizations turn to the users, often using one-to-many and

automated communication. For instance, organizations specify their problem, or what kind of information they look for, and invite users through an open call to participate in crowdsourcing tournaments. Users then self-select and submit their solutions and ideas. Afterwards, the input provided by users will be assessed internally and used for in-house foresight purposes. Moreover, organizations can interrogate users by means of interviews or surveys, or use prediction markets to let users bet on the likelihood of possible future events.

Moreover, some methods are available that allow organizations to passively obtain future-knowledge from users. The role of the user is confined to being an observee, as there is no exchange, communication or interaction at all. Instead, these methods rely solely on observation of online user dialogue and postings, which are generally available publicly in communities and social media. For instance, firms can screen tweets and blog entries of lead users or analyze data retrieved from social networks or online communities to systematically identify future-related information. One advantage of these methods is that increasing amounts of such data are publicly available and can often be accessed at no cost. Kozinets (2002) has pointed out that the strength of netnography lies in its unobtrustive nature, which provides a source of unbiased customer opinions. This argument can be generalized to all mentioned passive open foresight methods. On the other hand, the unobtrusiveness gives rise to ethical concerns about monitoring people's behavior without their consent (Kozinets, 2002). Moreover, while information can be retrieved at low cost, a high effort and investment may be required for protecting the privacy and confidentiality of users.

\subsection{High Level of Control vs. Self-Organization}

Third, interactive and unilateral sourcing methods differ as to the degree of control they leave a company to manage and maintain control over the direction of activities taking place. Thus, one may differentiate between self-organized or more directed forms of governance. This classification does not apply to passive methods: Online dialogue and expressions are observed, but are not influenced so that no governance of user behavior takes place.

When firms involve external sources into their innovative activities and invite volunteer users to 
contribute their knowledge, they cannot apply traditional organizational hierarchy or leadership authority to directing, incentivizing, or monitoring volunteers' efforts (Wallin \& von Krogh, 2010). Many open innovation methods, which can also be applied to foresight, rely on the self-organization of users. This particularly applies to community and social network-based approaches or collaboration-based crowdsourcing, which are essentially characterized by broad participation and self-determined collaboration of users. Using the example of Wikipedia, Cachia et al. (2007) point out that, when contributors act within a well-structured framework, they can gain control of objectives with minimal infrastructure and monitoring and are able to cope with diversity, controversy, and inconsistency. A disadvantage from the firm's perspective is, however, that communities tend to take up problems of interest to them, giving firms only limited leeway to select, propose and effectively broadcast specific problems (Felin \& Zenger, 2014). In contrast, in tournament-based crowdsourcing, firms can clearly specify their problem and the types of input they seek. The organization defines the terms (e.g. duration of call, evaluation criteria), then the users self-select to participate and submit solutions, suggestions and ideas. After the tournament deadline, the organization assesses the submissions and offers a reward to the user with the best contribution. However, while self-selection is assumed to attract suitable participants, the seeking firm has no direct control over the selection of participants (Afuah, 2014).

In communities, the degree of control depends largely on the firm's role. A higher level of control to guide the activities of users towards achieving firm-level objectives can be exerted if the organization assumes a privileged role (West \& Lakhani, 2008). As long as a firm uses a platform owned or maintained by third parties, it never has the same amount of control as in case of a proprietary platform (Dubiel et al., 2014). If the firm creates its own platform, it has more power to control membership and circumvent risks. On the other hand, if a firm exerts too much control, users may withdraw from the community, which will destroy the productive setting. While a firm may be tempted to control the work of voluntary contributors by demanding higher productivity, this may weaken people's motivation to contribute out of fun, learning, or recognition (Wallin \& von Krogh, 2010). The governance structure influences the level of contributions, and it has been found that the more open a project is, the more emphasis needs to be put on a 'fair" governance structure (Shah, 2006). Further methods involving more directed forms of governance include workshops with lead users.

\subsection{Intrinsic vs. Extrinsic Incentives for Participation}

Fourth, methods rely on different incentives to motivate users to contribute to foresight and freely reveal their knowledge. Both intrinsic and extrinsic motivations may come into play. Again, this classification is irrelevant for passive methods, where users are typically unaware of being observed.

A general issue in open innovation is the circumstance that knowledgeable individuals work outside the company and that less powerful incentives are available to motivate them (Wallin \& von Krogh, 2010). A particular challenge, which also affects foresight, is therefore to incentivize participation of users and keep up their interest. Previous research (Füller, 2007; Rohrbeck et al., 2010) identified different motivation sources of users, who virtually participate in innovation processes. According to their findings, methods for customer/user integration build on (1) the 
enjoyment of the interaction itself, which satisfies the user's need for entertainment and curiosity; (2) the enjoyment of being part of a group and the need for social recognition; (3) the personal need and product usage as users expect to benefit from being able to use a new or enhanced product later on; and (4) monetary incentives. Among these motivations, entertainment and curiosity were found to be the strongest drivers for participation (Rohrbeck et al., 2010). Thus, if the interaction meets the users' expectations and their contributions are taken seriously they will be willing to participate (Füller \& Matzler, 2007).

Most described methods for sourcing future-related knowledge from users rely predominantly on the intrinsic motivation of users. For instance, users, who are active in communities and social networks or contribute to collaboration-based crowdsourcing, are strongly motivated by the interest in certain topics and enjoy social exchange and discussion with peers about their topic of interest. In order to preserve the contributors' motivation, Hiltunen (2011) highlighted (in the case of Finpro's crowdsourced TrendWiki) the importance of giving feedback to contributors. Another intrinsic motivation is fun, which plays an important role in collaborative forecasting games that incentivize users to participate by entertaining them (Schatzmann et al., 2013). Gamification holds potential to particularly get those individuals involved, who have not yet dealt with foresight or are not interested in future-related issues (Watkins \& Neef, 2016).

In methods, which involve lead users, the potential use of a novel solution that caters to their needs provides a strong incentive for revealing information and contributing to innovative activities. Although foresight does not aim at the development of new products and services in the short run and the innovation-related benefit may be weaker, it is still relevant to motivate lead users to share their future-related knowledge. Lead users might feel honored to participate or simply enjoy the creative task (Lühtje \& Herstatt, 2004). However, if intrinsic motivation does not suffice, additional monetary incentives can be used to extrinsicially motivate them to cooperate with the firm in foresight workshops and compensate for their efforts. Further methods, which rely on a mix of intrinsic and extrinsic motivations, include tournament-based crowdsourcing: While non-monetary factors continue to play a role, a price is announced to reward the winning solution or idea and, thereby, incentivize users to participate. A strong financial incentive is at work in prediction markets, where users are incentivized to participate and reveal information as they expect to win money for successful forecasting and trading performance. Graefe et al. (2010) highlight that prediction markets trick participants to continuously challenge the group opinion and look for superior information, as participation is only beneficial if one does not agree with, and is able to improve, the current forecast.

In addition to intrinsic and extrinsic motivations, Franke et al. (2013) found that, apart from potential participants calculating whether participation will pay off, there is also a subjective evaluation of fairness. Accordingly, the individual's propensity to submit a contribution increases when they get a fair share and have a voice in decisions.

\section{Conclusion}

Advances in information and communication technologies have facilitated new methods to source knowledge beyond organizational boundaries. Many of these methods known from open innovation can also be applied to foresight to source knowledge from external sources. This article 
focuses on users as one particular external knowledge source. The contributions of this paper are threefold. First, the paper reviewed literature on open and user innovation and identified arguments why users can be a valuable source of insight into future demands, preferences and behavior. Accordingly, users, and particularly lead users, have superior knowledge as they know their needs best and integrating their diverse perspectives may help broaden the search space and minimize the risk of overlooking harmful developments or missing promising opportunities. Second, the paper identifies and typologises methods that are suitable for drawing on user knowledge. It includes methods from open and user innovation as well as methods known from traditional foresight that can now be conducted in significantly more open ways. Third, the paper analyses and juxtaposes these methods in regards to their advantages, disadvantages and boundary conditions. Thus, this section is particularly relevant for practitioners, who seek to integrate user knowledge into their foresight process and need guidance on selecting the right method, which is most appropriate for their goals.

Open innovation has induced a paradigm shift (Baldwin \& von Hippel, 2011), which is now also affecting foresight practice. Similarly, foresight methods will increasingly rely on knowledge of external actors and thereby develop into a more open direction. It appears that the expertise of a limited number of individuals, such as experts, loses influence in favor of collective intelligence. Cachia et al. (2007) highlight a change in trust patterns: "While, some years ago people would only trust reputable encyclopedias written by experts acknowledged in their respective fields, now people are also confident in the collaborative work of anonymous contributors" (p. 1190f.). Moreover, increasing amounts of user dialogue available online are being analyzed for foresight, which will lead foresight to become more data-driven.

The methods discussed in this article have different strengths and weaknesses and the selection of a suitable method depends on the firm's specific objectives. In addition, these methods often supplement each other and can be combined. For instance, an online community can be used to post an open call for participation in crowdsourcing tournaments or prediction markets. Another example refers to the identification of lead users in social networks and communities (Belz \& Baumbach, 2010; Brem \& Bilgram, 2015) or prediction markets (Spann et al., 2009), which are then invited to discuss possible alternative futures with internal employees face-to-face in foresight workshops.

Little research on open foresight has been conducted yet. More research is needed to investigate under which conditions methods work best. Moreover, in the context of open innovation, West and Bogers (2014) pointed out that the identification and acquisition of innovations is only one part and that, in order to benefit from external sources, the innovations must be fully integrated into the firm's R\&D activities. A similar issue applies to foresight, as foresight is not just about developing visions about possible alternative futures, but also using the knowledge to take the right action. 


\section{References}

Afuah, A. (2014). Business model innovation: Concepts, analysis, and cases. Routledge: New York.

Afuah, A., Tucci, C. L. (2013). Value Capture and Crowdsourcing. Academy of Management Review, 38(3), 457-460.

Amsteus, M. (2008). Managerial foresight: Concept and measurement. Foresight, 10(1), 5366.

Ansoff, H. I. (1975). Managing strategic surprise by response to weak signals. California Management Review, 18(2), 21-33.

Asur, S., Huberman, B. A. (2010). Predicting the future with social media. Web Intelligence and Intelligent Agent Technology (WI-AIT).

Baldwin, C, von Hippel, E. (2011). Modeling a paradigm shift: From producer innovation to user and open collaborative innovation. Organization Science, 22(6), 1399-1417.

Bayus, B. L. (2013). Crowdsourcing mew product ideas over time: An analysis of the Dell Idea Storm community. Management Science, 59(1), 226-244.

Belonzon, S., Schankermann, M. (2012). Motivation and Sorting in Open Source Software Innovation. Center for Economic Performance, London.

Belz, F.-M., Baumbach, W. (2010). Netnography as a method of lead user identification. Creativity and Innovation Management, 19(3), 304-313.

Boudreau, K., Lakhani, K. (2013). Using the crowd as an innovation partner. Harvard Business Review, 91(4), 60-69.

Brem, A., Bilgram, B. (2015). The search for innovative partners in co-creation: Identifying lead users in social media through netnography and crowdsourcing. Journal of Engineering and Technology Management, 37, 40-51.

Cachia, R., Compano, R., Da Costa, O. (2007). Grasping the potential of online social networks for foresight. Technological Forecasting and Social Change, 74(8), 1179-1203.

Cassiman, B., Di Guardo, M. C., Valentini, G. (2010). Organizing links with science: Cooperate or contract? A project-level analysis. Research Policy, 39(7), 882-892.

Chesbrough, H. (2003). Open innovation: The new imperative for creating and profiting from technology. Harvard Business School Press: Boston, MA.

Cohen, W. M., Levinthal, D. A. (1990). Absorptive capacity: A new perspective on learning and innovation. Administrative Science Quarterly, 35(1), 128-152.

Cuhls, K. (2012). Zu den Befragungen zwischen Delphi Befragungen und "einfachen" Zukunftsbefragungen. In: Popp (ed.): Zukunft und Wissenschaft. Springer, Berlin and Heidelberg. 
Cyert, R. M., March, J. G. (1963). A behavioral theory of the firm. Englewood Cliffs, NJ: Prentice-Hall.

Daheim, C., Uerz, G. (2008). Corporate foresight in Europe: from trend based logistics to open foresight. Technology Analysis and Strategic Management, 20(3), 321-336.

Dahlander, L., Gann, D. M. (2010). How open is innovation. Research Policy, 39, 699-709.

Day, G. S., Schoemaker, P. J. H. (2005). Scanning the periphery. Harvard Business Review, 83(11), 135-140.

Diener, K. (2014). Organizing collaborative innovation, Studying the process of intermedaries for open innovation. Disseration, RWTH Aachen.

Dodgson, M., Gann, D. M., Salter, L. (2006). The role of technology in the shift towards open innovation: the case of Procter \& Gamble. RED Management, 36(3), 333-346.

Drexler, G., Duh, A., Kornherr, A., Korosak, D. (2014). Boosting open innovation by veveraging big data. In: Griffin, Noble, Dumusoglu (eds.): Open innovation, new product development essentials from the PDMA, 299-318.

Dubiel, A., Brexendorf, T. O., Glöckner, S. (2014). Keeping up with the virtual voice of the customer - social media applications in product innovation. In: Griffin, Noble, Dumusoglu (Eds.): Open innovation, new product development essentials from the PDMA, 57-79.

Ehls, D., Korreck, S., Jahn, R., Zeng, M., Heuschneider, S., Herstatt, C., Koller, H., Spaeth, S. (2016). Open foresight: Exploiting information from external sources. Available at https://ssrn.com/abstract=2764208 (Accessed June 11, 2018).

Fabrizio, K. R. (2009). Absorptive capacity and the search for innovation. Research Policy, $38(2), 255-267$.

Felin, T., Zenger, T. R. (2014). Closed or open innovation? Problem solving and the governance choice. Research Policy, 43, 914-925.

Franke, N., Poetz, M. K., Schreier, M. (2013). Integrating problem solvers from analogous markets in new product ideation. Management Science, 60(4), 1063-1081.

Franke, N., Shah, S. (2003). How communities support innovative activities: an exploration of assistance and sharing among end-users. Research Policy, 32, 157-178.

Füller, J. (2007). What motivates creative consumers to participate in virtual new product development? Conference of the American Marketing Association, Washington, DC.

Füller, J., Jawecki, G., Bartl, M. (2006). Produkt- und Serviceentwicklung in Kooperation mit Online Communities. In: Hinterhuber, H. H., Matzler, K. (Eds.): Kundenorientierte Unternehmensführung, Wiesbaden: Gabler.

Füller, J., Matzler, K. (2007). Virtual product experience and customer participation - A chance for customer-centred, really new products. Technovation, 27(6-7), 378-387.

Füller, J., Mühlbacher, H., Matzler, K., Jawecki, G. (2009). Consumer empowerment through internet- based co-creation. Journal of Management Information Systems, 26 (3), 71-102. 
Gassmann, O., Sandmeier, P., Wecht, C. (2006). Extreme customer innovation in the frontend: Learning from a new software paradigm. International Journal of Technology Management, 33(1), 46-66.

Georghiou, L. (2001). Third Generation Foresight: Integrating the Socio-Economic Dimension. Proceedings of the International Conference on Technology Foresight, Science and Technology Foresight Center of NISTEP, Japan, March.

Graefe, A., Luckner, S., Weinhardt, C. (2010). Prediction markets for foresight. Futures, 42(4), 394-404.

Gattringer, R., Strehl, F. (2014a). The role of pre-foresight phase in open foresight processes. 5th International Conference on Future-Oriented Technology Analysis (FTA), Brussels.

Gattringer, R., Strehl, F. (2014b). Open foresight process for identifying innovation opportunities. Proceedings of the REDD Management Conference, Stuttgart.

Grimpke, C., Sofka, W. (2009). Search patterns and absorptive capacity: Low- and hightechnology sectors in European countries. Research Policy, 38(3), 495-506.

Hanke, C., Möhrle, M. G. (2013). Scenario 2.0: What weblogs reveal about the future of mobility. 9th Symposium for Forecasting and Technology Planning, Berlin.

Harryson, S., Klinknaite, S., Dudkowski, R, (2008). Flexibility in innovation through external learning: exploring two models for enhanced industry-university collaboration. International Journal of Technology Management, 41(1-2), 109-137.

Heger, T., Boman, M. (2015). Networked foresight - The case of EIT ICT Labs. Technological Forecasting 85 Social Change, 101, 147-164.

Hiltunen, E. (2011). Crowdsourcing the future: The foresight process at Finpro. Journal of Future Studies, 16(1), 189-196.

Hines, A., Bishop, P. (2013). Framework foresight: Exploring futures the Houston way. Futures, $51,31-49$.

Horton, A. (1999). A simple guide to successful foresight. Foresight, 1(1), 5-9.

Howe, J. (2006). The rise of crowdsourcing. Wired, 14(6), 176-183.

Huizingh, E. (2011). Open innovation: State of the art and future perspectives. Technovation, $31,2-9$.

Janzik, L., Raasch, C. (2011). Online communities in mature markets: Why join, why innovate, why share? International Journal of Innovation Management, 15(4), 797-836.

Jeppesen, L. B., Lakhani, K. (2008). Marginality and problem-solving effectiveness in broadcast search. Organization Science, 21(5), 1016-1033.

Katila, A. (2002). New product search over time: Past ideas in their prime? Academy of Management Journal, 45(5), 995-1010.

Katila, A., Ahuja, G. (2002). Something old, something new: A longitudinal study of se- 
arch behavior and new product development. Academy of Management Journal, 45(6), 11831194.

Kim, A. (2000). Community building on the web. Peachpit Press, Berkeley, CA.

Könnölä, T., Brummer, V., Salo, A. (2007). Diversity in foresight: Insights from the fostering of innovative ideas. Technological Forecasting and Social Change, 74(5), 608-626.

Kozinets, R. V. (1998). On netnography: Initial reflections on consumer research investigations of cyberculture. Advances in Consumer Research, 25, 366-371.

Kozinets, R. V. (2002). The field behind the screen: Using netnography for marketing research in online communities. Journal of Marketing Research, 39, 61-72.

Kozinets, R. V. (2010). Netnography: doing ethnographic research online. Sage: London.

Lakhani, K. R., von Hippel, E. (2003). How open source software works: "Free" user-to-user assistance. Research Policy, 32(6), 923-943.

Li, Y., Vanhaverbeke, W. (2009). The effects of inter-industry and country difference in supplier relationships on pioneering innovations. Technovation, 29(12), 843-858.

Lilien, G. L., Morrison, P. M., Searls, K., Sonnack, M., von Hippel, M. (2002). Performance assessment of the lead user idea-generation process for new product development. Management Science, 48(8), 1042-1059.

Lim, Chesbrough, H., Ruan (2010). Open innovation and patterns of R\&D competition. International Journal of Technology Management, 52(3-4), 295-321.

Lüthje, C., Herstatt, C. (2004). The lead user method: An outline of empirical findings and issues for Future Research. RED Management, 34(5), 553-568.

Magruk, A. (2011). Innovative classification of technology foresight methods. Technological and Economic Development of the Economy, 17(4), 700-715.

Miemis, V., Smart, J., Brigis, A. (2012). Open foresight. Journal of Future Studies, 17(1), 91-98.

Miles, I. (2010). The development of technology foresight: A review. Technological Forecasting and Social Change, 77(9), 1448-1456.

Mietzner, D. (2009). Strategische Vorausschau und Szenarioanalysen: Methodenevaluation und neue Ansätze. Gabler: Wiesbaden.

Morrison, P. D., Roberts, J. H., Midgley, D. F. (2004). The nature of lead users and measurement of leading edge status. Research Policy, 33, 351-362.

Morrison, P. D., Roberts, J. H., von Hippel, E. (2000). Determinants of user innovation and innovation sharing in a local market. Management Science, 46, 1513-1527.

Nelson, R. R., Winter, S. G. (1982). An evolutionary theory of economic change. Harvard University Press, Cambridge, MA.

Piezunka, H., Dahlander, L. (2015). Distant search, narrow attention: How crowding alters 
organizations' filtering of suggestions in crowdsourcing. Academy of Management Journal, 58(3), 856-880.

Popper, R. (2008). How are foresight methods selected? foresight, $10(6), 62-89$.

Prahalad, C. K., Ramaswamy, V. (2004). The future of competition: Co-creating unique value with customers. Harvard Business School Press, Boston.

Rau, C., Schweitzer, F., Gassmann, O. (2014): Open foresight workshops for opportunity identification. In: Noble, Durmusoglu, Griffin (Eds.): Open innovation: new product development essentials from the PDMA, 27-52.

Reger, G. (2001). Technology foresight in companies: From an indicator to a network and process perspective. Technology Analysis \& Strategic Management, 13(4), 533-553.

Rohrbeck, R., Battistella, C., Huizingh, E. (2015). Corporate foresight: An emerging field with a rich tradition. Technological Forecasting and Social Change, 101, 1-9.

Rohrbeck, R., Kum, M. E. (2018). Corporate foresight and its impact on firm performance: A longitudinal analysis. Technological Forecasting \& Social Change, 129, 105-116.

Rohrbeck, R., Gemünden, H. G. (2011). Corporate foresight: Its three roles in enhancing the innovation capacity of a firm. Technological Forecasting and Social Change, 78, 231-243.

Rohrbeck, R., Steinhoff, F., Perder, F. (2010). Sourcing innovation from your customer: how multinational enterprises use Web platforms for virtual customer integration. Technology Analysis 83 Strategic Management, 22(2), 117-131.

Rudzinski, C. V., \& Uerz, G. (2014). Volkswagen: Open Foresight at the Front End of Research Innovation. In Management of the Fuzzy Front End of Innovation (pp. 295-299). Springer, Cham.

Sawney, M., Prandelli, E. (2000). Communities of creation: Managing distributed innovation in turbulent markets. California Management Review, 42, 24-54.

Schatzmann, J., Schäfer, R., Eichelbaum, F. (2013). Foresight 2.0 - Definition, overview and evaluation. European Journal of Futures Research, 1(15), 1-15.

Schiele, H. (2010). Early supplier integration: the dual role of purchasing in new product development. R \& D Management, 40(2), 138-153.

Schreier, M., Prügl, R. (2008). Extending lead-user theory: Antecedants and consequences of consumer's lead userness. Journal of Product Innovation Management, 25 (4), 331-346.

Shah, S. (2006). Motivation, governance, and the viability of hybrid forms in open source software development. Management Science, 52(7), 1000-1014.

Slaughter, R. A. (2002). Developing and applying strategic foresight. Manuscript, available at http://www.forschungsnetzwerk.at/downloadpub/2002slaughter_strategic_foresight.pdf (Accessed April 15, 2018)

Spann, M., Ernst, H., Skiera, B., Soll, J. H. (2009). Identification of lead users for consumer products via virtual stock markets. Journal of Product Innovation Management, 26(3), 322335. 
Stockinger, H. (2015). Open innovation research: Emerging of the digital era. Dissertation. Ulm University.

Stuart, T. E., Podolny, J. M. (1996). Local search and the evolution of technological capabilities. Strategic Management Journal, 17, 21-38.

Surowiecki, J. (2004). Why the many are smarter than the few and how collective wisdom shapes business, economies, societies and nations. Doubleday, New York.

Tapscott, D., Williams, A. D. (2006). Wikinomics: How mass collaboration changes everything. B\&T, New York.

Urban, G. L., von Hippel, E. (1988). Lead user analyses for the development of new industrial products. Management Science, 34(5), 569-582,

van der Duin, P., Heger, T., Schlesinger, M. (2014). Toward networked foresight? Exploring the use of futures research in innovation networks. Futures, 59, 62-78.

Vecchiato, R. (2012). Environmental uncertainty, foresight and strategic decision making: An integrated study. Technological Forecasting 86 Social Change, 79(3), 436-447.

von der Gracht, H., A., Banuls, V. A., Turoff, M., Skulimowski, A. M. J., Gordon, T. J. (2015). Foresight support systems: The future role of ICT for foresight. Technological Forecasting and Social Change, 97, 1-6.

von Hippel, E. (1986). Lead users: A source of novel product concepts. Management Science, 32(7), 791-805.

von Hippel, E. (1988). The sources of innovation. Oxford University Press: New York.

von Hippel, E. (1998). Economics of product development by users: The impact of "sticky" local information. Management Science, 44(5), 629-644.

von Hippel, E. (2005). Democratizing innovation. MIT Press: Cambridge, MA.

von Hippel, E., Franke, N., Prügel, R. (2009). Pyramiding: Efficient search for rare subjects. Research Policy, 38, 1394-1406.

von Krogh, G., Spaeth, S., Lakhani, K. R. (2003). Community, joining, and specialization in open source software innovation: A case study. Research Policy, 32(7), 1217-1241.

Voros, J. (2003). A generic foresight process framework. Foresight, 5(3), 10-21.

Wallin, M. W., von Krogh, G. (2010). Organizing for open innovation: Focus on the integration of knowledge. Organzational Dynamics, 39(2), 145-154.

Watkins, V., Neef, A. (2016). Playing into the future: How can strategic work relating to the future benefit from the gamification trend? http://www.z-punkt.de/uploads/files/11/gamification.pdf (Accessed April 15, 2018)

West, J., Bogers, M. (2014). Leveraging external sources of innovation: A review of research on open innovation. Journal of Product Innovation Management, 31(4), 814-831.

West, J., Lakhani, K. (2008). Getting clear about communities in open innovation. Industry and Innovation, 15(2), 223-231. 
Wiener, M. (2018). Open foresight: The influence of organizational context. Creativity and Innovation Management, 27, 56-68.

Wiener, M., Gattringer, R., Strehl, F. (2018). Participation in inter-organisational collaborative open foresight, A matter of culture. Technology Analysis \& Strategic Management, 30(6), 684700 .

Zeng, M. (2018). Foresight by online communities - The case of renewable energies. Technological Forecasting \& Social Change, 129, 27-42. 


\section{Biographies}

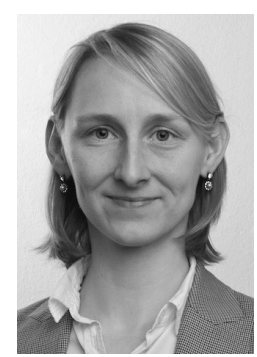

Sabrina Korreck. Sabrina Korreck is a research assistant and doctoral candidate at the Chair of Management and Digital Markets at University of Hamburg. She studied economics, political science and sociology in both Potsdam and Tampere (Finland) and completed the Advanced Studies Program at Kiel Institute for the World Economy. Prior to joining University of Hamburg she worked as a Research Associate at Hertie School of Governance and as Business Analyst in the Berlin startup scene. 